\title{
Rendición de cuentas en la gestión del sector público centralizado de Costa Rica
}

\author{
Accountability in the management of the centralized public sector in Costa Rica
}

\author{
Leonardo Salas
}

\section{Introducción}

Existe una gran necesidad en Costa Rica de una adecuada rendición de cuentas en la gestión pública, así lo dicen todos los estudios que reflejan las prioridades de la ciudadanía costarricense y que Villoria (2012) ratifica al decir que "un gobierno de calidad exige una burocracia profesional, con una ética profesional exigente y unas instituciones políticas que aseguren una eficaz rendición de cuentas".

Los distintos gobiernos han hecho esfuerzos en esta materia pero no se ha logrado superar etapas de principiante. Hay incongruencias entre la ley y su aplicación y no se ha evolucionado de manera constante hacia los niveles avanzados que requiere una democracia moderna, participativa e informada.

Como en otro tipo de democracias similares, en Costa Rica los medios de comunicación, los partidos políticos, las instituciones públicas y organizaciones no gubernamentales hacen referencia a muchos autores, teorías, análisis, descripciones, normativa y criterios generalizados, a nivel nacional e internacional, sobre el tema de la rendición de cuentas, confundiendo su manejo conceptual con los términos de transparencia, anticorrupción, entre otros.. Sin embargo, no existe en el país una medición objetiva y cuantitativa que permita valorar de una forma más concreta si las instituciones del sector público centralizado de Costa Rica avanzan o no en materia de rendición de cuentas.

Si no se conoce un problema y sus causas será difícil resolverlo efectivamente. Esto sucede en Costa Rica pues no es posible medir, con los instrumentos actuales, el estado de la rendición de cuentas a nivel público, por lo que la investigación trató de resolver la respuesta a la siguiente interrogante: ¿qué elementos debe considerarse para elaborar un índice de rendición de cuentas del sector público centralizado costarricense que permita llevar el pulso sobre este tema? El análisis se realizó en el periodo comprendido entre 2009 y 2012.

Esta interrogante fue planteada partiendo de la

*Dirección de correspondencia [Correspondence

address]: Leonardo Salas, Universidad de Chile

E-mail: ljsalasq@gmail.com hipótesis de que en Costa Rica no se hace una adecuada rendición de cuentas. Se afirma lo anterior por dos razones esenciales, la primera es que lo normado en las leyes costarricenses sobre esta materia es de nivel básico, es decir, le brinda al país una configuración inicial simple, dado que lleva a la Administración Pública a brindar información cuando así se le solicita, sin ir más allá. Dicho de otro modo, se presenta una rendición de cuentas reactiva, en espera de que se le demande información pero no va de la mano con una Administración dispuesta y preocupada por brindar información y comunicación constante a sus administrados.

La segunda razón para afirmar que en Costa Rica no se hace una adecuada rendición de cuentas, es que la Administración no tiene claro que cumplir la normativa básica es insuficiente. Se necesita además saber cómo dice que rinde cuentas y cómo realmente se está llevando a cabo dicho proceso.

\section{Metodología}

La investigación se deriva de la tesis de doctorado realizada por el autor y que fue presentada en julio del 2014 ante la Universidad Complutense de Madrid. En ella se encuentra una propuesta de índice de rendición de cuentas en la gestión del sector público centralizado de Costa Rica con el fin de contribuir al incremento de la transparencia y eficacia en sus funciones, logrando que se diagnostique el verdadero nivel en que se encuentra la rendición de cuentas de este sector, de modo que en etapas futuras se pueda ver los reales avances o retrocesos que haya en esta materia. El índice buscó medir valores como lealtad, probidad, responsabilidad, responsabilidad, conducirse apropiadamente, conocer prohibiciones, comportarse con decoro y respeto, excusarse de participar cuando hay conflictos de intereses, defender el interés público, evitar tráfico de influencias, aplicar principio de legalidad, evitar uso de bienes públicos en beneficio personal y eficiencia, etc., siguiendo las indicaciones de Serrano (2005)

La investigación describió la situación actual de la rendición de cuentas en la gestión pública costarricense, evidenciando qué se tiene y en qué se 
puede mejorar. Se hizo una revisión de la normativa vigente y consideraciones sobre los pasos dados en esta materia.

Se explicaron los principales fundamentos teóricos de la rendición de cuentas en materia de gestión pública que son la base para la construcción de los parámetros aplicados, se recurrió a diversos autores, nacionales e internacionales para construir el marco teórico correspondiente y de esa forma se extrajeron los diferentes parámetros para elaborar el índice de rendición de cuentas como el "deber ser" en esta materia para el caso costarricense.

Para aplicar el índice se escogieron dos ministerios dentro del sector público centralizado, valorando la similitud en cuanto a presupuesto y cantidad de personal, lo que llevó a seleccionar el de Ambiente y Energía (MINAE) y el de Agricultura y Ganadería (MAG).

La construcción del índice se hizo analizando la situación nacional, recopilando contenidos de diversos autores y teorías sobre rendición de cuentas, se establecieron parámetros deseables del índice y luego se aplicó a los ministerios señalados anteriormente. Esto permitió generar, de acuerdo a Ramió (1999), dos grandes divisiones, la de control interno y externo.

Valga decir, que la relación entre control y rendición de cuentas no es antojadiza, pues como bien se resume en Villasuso et al. (2005) al decir que el control "se presenta como uno de los instrumentos o medios más efectivos para pedir cuentas y evaluar los resultados de las gestiones del Presidente de la República y, en general, de todos los servidores públicos".

Volviendo a las divisiones, en la interna se establecieron cuatro dimensiones, la clásica, la de gestión, la organizativa y la judicial. En la externa fueron dos, la parlamentaria y la de auditorías externas.

Dentro de la interna, para cada una de las dimensiones se establecieron indicadores que dieran cuenta de su nivel de logro. En la dimensión Clásica se establecieron dos subdimenciones, una referida a la legalidad y otra referida a la formalidad. Estas dimensiones estaban compuestas por 12 preguntas sobre código de ética, rendición de cuentas en el plan institucional, funciones definidas, inventarios, seguimiento de recomendaciones de la Auditoría Interna, incompatibilidades públicas y privadas, beneficios para el denunciante e intermediarios indebidos.

En la dimensión de Gestión se establecieron tres subdimensiones, Economía, Eficacia y Eficiencia, que juntas reunían 17 preguntas relacionadas con recursos propios y disponibles, servicios, logros, impacto, actuaciones, equidad, entorno, trámites, tiempos, calidad, funciones, registros, compras y pagos.

Respecto a la dimensión Organizativa, sus subdimensiones fueron Estructuras, Procesos y Personal. Estuvo conformada por 24 preguntas en temas como ausentismo, rotación, capacitación, contratación de personal, valores, evaluación del desempeño, expedientes, interinazgo, puestos de confianza, informes de funciones, procesos de compras, archivo.

Por último, en la dimensión Judicial, se contemplaron temas de lo contencioso administrativo y constitucional, y tenía únicamente 3 preguntas sobre sanciones, investigaciones pendientes, registros, etc., debido a lo específico de su materia.

En las externas en tanto, encontramos que la dimensión Parlamentaria está compuesta por las subdimensiones Política, Económica y Atención de ciudadanos. Esta dimensión reunía 21 preguntas relacionadas con contralorías de servicios, atención de consultas, tiempos de respuesta, participación, apertura, informes, manejo del sitio web como herramienta de información.

Por último, para Auditorías externas, se analizan tanto a nivel de Instancias Administrativas como a Consultoras, y agregó 4 preguntas en temas de realización de auditorías, cumplimiento de recomendaciones y pertenencia a redes de transparencia.

El índice fue validado con el criterio de expertos y académicos, de modo que su aplicación permitió conjuntar las calificaciones de cada instrumento, obteniendo así una nota para cada uno de ellos y para cada dimensión en los ministerios estudiados.

El cuestionario contó con 81 preguntas de respuesta cerrada. Cuando la respuesta era Sí, obtuvo nota 100, en cambio, un No equivalía a 0. El 100 refleja que la institución sí cumple con ese indicador específico, por tanto, el 0 muestra que no se logró satisfacer el requerimiento del indicador.

El indicador también tenía un punto intermedio para no inflexibilizar su aplicación, es decir, cuando no estaba claramente definido el cumplimiento o ausencia de dicho indicador. Esto se reflejaba con una calificación parcial de 50, valorada de acuerdo a la ponderación que el investigador daba a las respuestas de los entrevistados y a la información encontrada. 


\section{Resultados}

Se constató que en general se tiene una baja calidad en la rendición de cuentas. Hay algunas luces y muchas sombras reflejadas en el promedio cercano a 50 que presentan ambas instituciones en ambas dimensiones. Según los resultados obtenidos, hay una cultura de rendición de cuentas poco consolidada. En general, todas las dimensiones giran alrededor de los 50 puntos, logrando de ese modo apenas la mitad del puntaje máximo.

Lo anterior se interpreta como un cumplimiento normal de los elementos mínimos de la rendición de cuentas (normativa básica reflejada por la dimensión clásica cuyas características básicas debería tener cualquier país democrático) pero al aplicar indicadores un poco más estrictos los ministerios no pasaron la prueba, reflejando también la confirmación de la hipótesis planteada en el sentido de que no se tiene una verdadera rendición de cuentas en el país.

Por otro lado, ninguna dimensión, excepto la clásica, obtuvo más de 70 puntos, es decir, se refleja que la rendición de cuentas en Costa Rica es muy deficiente si se somete a altos estándares de calidad.

En general, el promedio de 50 indica, por un lado, una inadecuada rendición de cuentas en el país, y por otro, que se cuenta al menos con alguna materia prima que se debe pulir para desarrollar un proceso de cumplimiento de los indicadores propuestos. Dicho de otra forma, en las dimensiones estudiadas la información evaluada por el índice no está completa del todo, hay que empezar a elaborarla y procesarla, o en otros casos, es información que se encuentra pero está desordenada y sin identificar.

De manera puntual, el MINAE obtuvo como promedio general 46,83 puntos; y el MAG 54,33 de 100 . Las peores calificaciones son de las dimensiones de auditoría externa y gestión. La primera estuvo en 25 puntos (del MINAE) y 13 (el MAG); la segunda con 28 (MINAE) y 44 (el MAG). El MAG supera en puntaje al MINAE no solo en el promedio general, sino en todas las dimensiones, a excepción, como ya se vio, de la auditoría externa; sin embargo, es necesario enfatizar que lo anterior no significa que los resultados del MAG sean favorables o al menos decorosos.

\section{Conclusiones}

El MINAE tiene un bajo rendimiento en la dimensión de gestión, la organizativa y de auditorías externas, por tanto, necesita revisar sus indicadores internos sobre esos temas, así como el cumplimiento y la definición de medidas a corto plazo que permitan lograr ese tipo de indicadores.

También dentro de la dimensión de gestión del MINAE es indispensable señalar que no basta con tener datos aislados sino sistematizarlos en indicadores de economía, eficacia y eficiencia.

Otro aspecto específico de ambos ministerios, es que la presentación de informes de gestión, a nivel interno y externo, es únicamente de los jerarcas, porque la ley así los obliga. Sin embargo, lo ideal es que todo aquel que haya estado en puesto de confianza, consultores, personal interino o en propiedad, rindiera un informe de sus labores cuando culmine su relación con la organización, porque aunque ocupara un puesto de confianza tuvo incidencia en el uso, administración, custodia de bienes y servicios públicos.

También como elemento común entre los dos ministerios es que solo envían informes a la Defensoría de los Habitantes y a la Asamblea Legislativa cuando la normativa los obliga o cuando hay algún tema polémico que activa estos mecanismos de control. No obstante, tal como se insistió a lo largo de la investigación, lo ideal es una rendición de cuentas activa y permanente que se anticipe a las reacciones o demandas de actores sociales e institucionales.

Otro aspecto deficiente en ambos ministerios, que atenta contra la correcta administración de la información, es el estado físico en que se encuentran los archivos institucionales. Dicha situación refleja la realidad que se tiene en todo el sector público en esta materia, que va desde el desconocimiento de la legislación archivística hasta la ignorancia de las funciones que cumplen los archivos de las organizaciones públicas en el manejo de la información.

Sería injusto decir que todo es negativo. Aunque pocos, hay algunos aspectos positivos y que se presentan en ambos ministerios en el tema de acercamiento a las comunidades; tanto el MAG como el MINAE realizan ferias, actividades comunales y ejercen funciones por medio de oficinas regionales que tienen en varios puntos del país.

También relacionado con el acercamiento a la ciudadanía, otro elemento positivo es el uso de las páginas web de cada institución. Esta herramienta de información podría ser aprovechada de mejor manera para mostrar una comunicación más integral y de interés para la ciudadanía pues aspectos básicos como presupuestos, actualización de actividades, chats en línea, denuncias, etc., no se encuentran dentro de estas páginas y su inoperancia retrasa la información oportuna e impide una mejora en los 
trámites.

Como se puede apreciar, la utilidad del índice propuesto puede tener impacto público. Si se utilizase el índice para todo el sector público no solo se podría cuantificar cada dimensión sino que los medios de comunicación también tendrían a la mano una serie de datos para poner al alcance de la población y así evidenciar de mejor forma las irregularidades en la gestión pública.

Sin embargo, este índice no es solamente para ver los errores, sino que pretende, dentro de otras cosas, contribuir a la transparencia en varios aspectos como manejo de información, publicación de documentos, atención ciudadana, controles horizontales y verticales, uso de herramientas como páginas web, cumplimiento de normativa, entre otras. Todo esto sirve además como mecanismo que genera ciertas alertas para mejorar eficacia en la función pública costarricense.

Finalmente, lo más importante de la investigación es que busca consolidarse como un instrumento de mejora en la rendición de cuentas por lo que se reitera la importancia de que se siga aplicando y generalizando a todo el sector público costarricense, de manera anual y gradual, como medida de verificar el cumplimiento y avance de los indicadores propuestos. No obstante, todo este proceso debe ser apoyado por una ciudadanía más educada, activa y demócrata que demande mayor información y participación.

\section{Referencias}

Ramió, C. (1999). Teoría de la Organización y Administración Pública. Editorial Tecnos, Madrid.

Serrano, C. (2005). La corrupción como fenómeno social en Costa Rica. Sistema Editorial y de Difusión Científica de la Investigación, Universidad de Costa Rica, San José.

Villasuso, V. E., Flores, F. J., y Arroyo, M. V. (2005). Corrupción: más allá de las percepciones. Friedrich Ebert Siftung.

Villoria, M. (2012). Transparencia y gobierno abierto ¿qué gobierno quiere el gobierno abierto? Ponencia Presentada en el XVII Congreso Internacional del CLAD sobre la Reforma del Estado y de la Administración Pública, Cartagena, Colombia. 